\title{
OPTIMIZATION OF REPLACED NOZZLE DIAMETER FOR MINIMUM CLEANING COST DURING ABRASIVE BLASTING WITH QUARTZ SAND
}

\section{DR. TRAN THI HONG ${ }^{1}$, DR. DO THE VINH ${ }^{2}$, DR. TRAN NGOC GIANG ${ }^{3} \&$ DR. VU NGOC PI ${ }^{4 *}$}

${ }^{I}$ Associate Professor, Center of Excellence for Automation and Precision Mechanical Engineering, Nguyen Tat Thanh University, Ho Chi Minh City, Vietnam

${ }^{2,3,4}$ Assistant Professor, Mechanical Engineering Faculty, Thai Nguyen University of Technology, Thai Nguyen City, Vietnam

\section{ABSTRACT}

Sandblasting is a process of smoothing, shaping, and cleaning hard surfaces which is widely used in industry. In this research, the optimization of replaced nozzle diameter during abrasive blasting with quartz sand was carried out with the aim of reducing cleaning cost. For this purpose, an analysis was performed to find the minimum value of the cleaning cost obtained by determining the appropriate replaced nozzle diameter. Additionally, a series of meticulous experiments were conducted to investigate different factors including the initial diameter, the wear rate and the changing time for a nozzle, the compressor power, the cost of machine, nozzle and sand, and the effect of these factors on the optimum replaced nozzle diameter. As shown in the results, the initial nozzle diameter is the main factor affecting the optimum replaced nozzle diameter. Finally, an empirical model was developed for calculating the optimum replaced nozzle diameter.

KEYWORDS: Non-traditional machining, Sand blasting, Optimum nozzle diameter, Tungsten carbide nozzle, Cost optimization

Received: Sep 20, 2020; Accepted: Oct 11, 2020; Published: Jan 12, 2021; Paper Id.: IJMPERDDEC202086

\section{INTRODUCTION}

Sandblasting is a cleaning method commonly used for cleaning hard surfaces to prepare for painting or rust removal in industries such as shipbuilding and automobile manufacturing etc. This cleaning method was invented in 1870 by Benjamin C. Tilghman. In his system, the abrasive particles are pushed away by a partial vacuum generated by the compressed air in the nozzle tube. Also, the stream of abrasive particles is accelerated by the aid of compressed air down on to a surface to clean it $[1,2]$. In fact, the world's demand for abrasives increases every year. A recent report stated that, the world's demand for abrasives in 2014 was only \$8.6 billion while in 2019 was $\$ 11.4$ billion [3]. Therefore, it is necessary to reduce the abrasive cost in manufacturing processes as well as in sand blasting. Hence, this subject has attracted a number of scientists and manufacturers.

In a study of M.J. Woodward and R.S. Judson [4], a comparison of costs between wet abrasive blasting and dry blasting was conducted. The impacts of factors including water pressure, water flow rate, abrasive flow rate and nozzle stand-off distance on costs for each type of abrasive blasting system were analyzed. The results showed a distinct advantage of the cost of wet abrasive blasting over that of dry blasting. In a research of James D. Hansink [5], the author performed a cost comparison between blasting with garnet and coal slag and between new and recycled garnet. He concluded that the garnet could be recycled three times after blasting and the first recycled 
garnet used was received the lowest cost. A typical cost structure of a water blast-cleaning system was presented by W. Momber [6]. The author reported the costs for different components, of which the labor costs the most with $46.6 \%$. Besides, a high-pressure unit costs $18.6 \%$, whereas the costs of the fuel, the nozzle wear, and the high-pressure guns are $15 \%, 13.4 \%$, and $3.3 \%$ respectively. The water treatment system is invested at the lowest cost at $3.1 \%$. A study on cost optimization of the abrasive blasting system was conducted by N.P Vu and A.M. Hoogstrate [7]. The influence of many parameters of the abrasive blasting process (the air pressure, the initial nozzle diameter, the nozzle wear, etc.) on the cleaning cost was investigated. The models for calculation of the optimal nozzle diameter to obtain the minimum cleaning cost were presented. Both the cost and time of the blasting process were greatly reduced when applying the nozzle diameter optimization model. Similar results were provided in [8]. Summary, optimized nozzle diameter is the key to cost reduction, increased profits, and reduced cleaning time.

From the above analysis, it can be noted that the Design of Experiment technique to study the effect of sandblasting process parameters on optimal responses has not been used in previous studies. The application of this technique can effectively figure out the effect of input process factors as well as determine the optimum responses in any machining process such as in electrical discharge machining process [9-11], in wire discharge machining processes [1214], in grinding process [15-18], or in turning proces [19, 20]. Therefore, it is essential to carry out regression analysis and analysis based on the main effect diagram in the machining processes.

This article introduces a study on optimization of replaced tungsten carbide nozzle diameter for minimum cleaning costs during abrasive blasting with quartz sand. Additionally, the effects of the factors including initial nozzle diameter, nozzle wear rate, time for changing a nozzle, compressor power, machine cost, nozzle cost, and cost of sand on the optimum replaced nozzle diameter were investigated. Further, an empirical model was developed to obtain the optimum replaced nozzle diameter.

\section{METHODOLOGY}

In abrasive blasting, the cost of cleaning one square meter $\mathrm{C}_{\mathrm{cl}}(\mathrm{USD} / \mathrm{m} 2)$ is determined by (1):

$$
\mathrm{C}_{\mathrm{cl}}=\left(\mathrm{C}_{\mathrm{m}, \mathrm{h}}+\mathrm{C}_{\mathrm{a}, \mathrm{h}}+\mathrm{C}_{\mathrm{n}, \mathrm{h}}\right) / \mathrm{v}_{\mathrm{cl}}
$$

Where, $C_{m, h}, C_{a, h}$ and $C_{n, h}$ are the costs of the cleaning system, the abrasive and the nozzle per hour (USD/h), respectively; $\mathrm{v}_{\mathrm{cl}}$ is the cleaning rate $\left(\mathrm{m}^{2} / \mathrm{h}\right)$.

The abrasive cost is calculated as:

$$
\mathrm{C}_{\mathrm{a}, \mathrm{h}}=3600 \cdot \dot{\mathrm{m}}_{\mathrm{a}} \cdot \mathrm{C}_{\mathrm{a}, \mathrm{m}}
$$

Where, $\mathrm{C}_{\mathrm{a}, \mathrm{m}}$ is the abrasive cost per kilogram (USD/kg); $\dot{\mathrm{m}}_{\mathrm{a}}$ is the abrasive mass flow rate $(\mathrm{kg} / \mathrm{h})$ that can be achieved by the regression equation (with $\mathrm{R}^{2}=0.998$ ):

$$
\dot{\mathrm{m}}_{\mathrm{a}}=15.14 \cdot \mathrm{d}_{\mathrm{n}}^{-0.0214} \cdot \mathrm{P}^{1.0359}
$$

The nozzle cost per hour is calculated by (4):

$$
C_{n, h}=C_{n, p} / L_{n}
$$

Where, $C_{n, p}$ is the nozzle cost per piece (USD/piece); $L_{n}$ is the nozzle lifetime (h). 
For tungsten carbide, the nozzle lifetime lasts from 300 to 400 (h) [21]. With tungsten carbide nozzle, a nozzle will be replaced when it wears $1 / 16$ inch (or $1.59 \mathrm{~mm}$ ) beyond its original size [22]. Therefore, the wear rate WR is calculated by the following equation:

$$
\mathrm{WR}=1.59 / \mathrm{L}_{\mathrm{n}}=1.59 /(300 \div 400) \approx 0.004 \div 0.0053(\mathrm{~mm} / \mathrm{h})
$$

As shown in the data of Norton Sandblasting Equipment[21], the regression equation (with $\mathrm{R}^{2}=0.9984$ ) was used to calcalate the cleaning rate $\mathrm{v}_{\mathrm{cl}}$ :

$$
\mathrm{v}_{\mathrm{cl}}=6.6101 \cdot 10^{-6} \cdot \mathrm{d}_{\mathrm{n}}^{2.0121} \cdot \mathrm{p}^{1.5988}
$$

Where $\mathrm{p}$ is the air pressure $(\mathrm{kPa})$; the regression equation (with $\mathrm{R}^{2}=0.9774$ ) was applied to calculate the air pressure:

$$
\mathrm{P}=3854.7 \cdot \mathrm{d}_{\mathrm{n}}^{-2.5783} \cdot \mathrm{P}^{1.1801}
$$

Where $\mathrm{P}$ is the power $(\mathrm{kW}) ; \mathrm{d}_{\mathrm{n}}$ is nozzle diameter $(\mathrm{mm})$.

Figure 1 shows that air pressure depends heavily on the nozzle diameter. When the nozzle diameter increases (or the nozzle lifetime increases), the air pressure decreases. The cleaning rate is dependent on the nozzle diameter and air pressure according to Equation 3. Also shown in Figure 2, the cleaning rate grows significantly with an increase in the nozzle diameter.

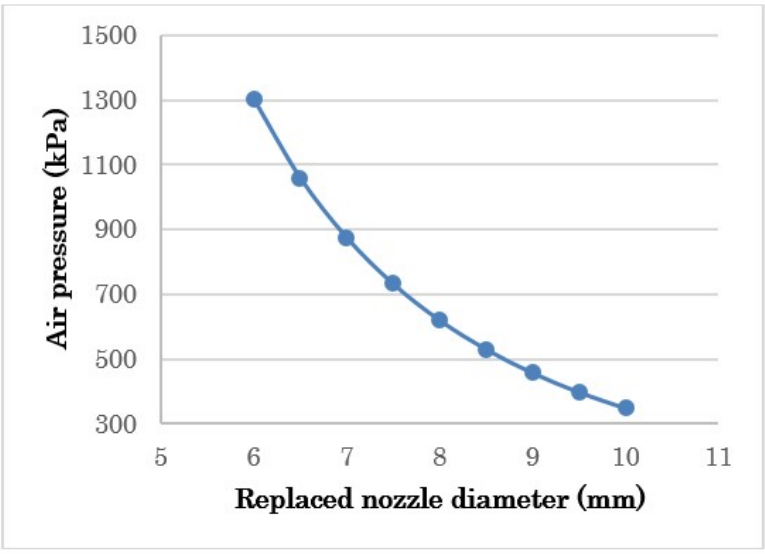

Figure 1: Dependence of the air pressure on the nozzle diameter

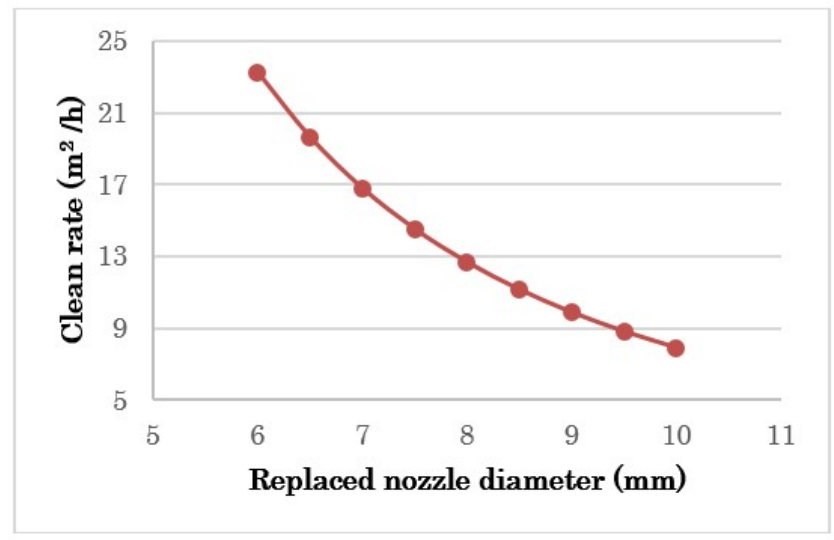

Figure 2: Dependence of the cleaning rate on the nozzle diameter 
Figure 3 depicts the relationship between the cost of cleaning for one square meter and nozzle diameter (With parameters fixed as $\left.C_{m, h}=20 \mathrm{USD} / \mathrm{h} ; C_{a, h}=0.5 \mathrm{USD} / \mathrm{kg} ; C_{n, p}=50 \mathrm{USD} / \mathrm{piece} ; W R=0.004 \mathrm{~mm} / \mathrm{h} ; P=20 \mathrm{~kW}\right)$. As shown in Figure 3, the cleaning cost is dependent greatly on the replaced nozzle diameter. Besides, there is a replaced nozzle diameter (called the optimum replaced nozzle diameter $d_{o p}$ ) on the chart at which the cleaning cost is minimum. If replacing the nozzle with this optimal value of diameter is applied (in this case $d_{o p}=12.2 \mathrm{~mm}$ ), the cleaning cost is much smaller $(22.56 \%)$ compared to replacing the nozzle in the normal way (conventional replaced nozzle diameter is $13.9 \mathrm{~mm}$ ).

According to the analysis above, a program was built to optimize problems for cost. In the problem, seven input parameters including initial nozzle diameter, nozzle wear rate, time for changing a nozzle, compressor power, machine cost, nozzle cost, and cost of sand were investigated for determining the optimum replaced nozzle diameter. The optimal problem can be shown as in the equation (8):

$$
\min C_{c l}=\operatorname{minf}\left(d_{n}\right)
$$

With the following constraints:

$$
\begin{aligned}
& 5 \leq d_{n 0} \leq 12.5 \\
& 0.004 \leq W R \leq 0.0053 \\
& 4 \leq P_{c} \leq 80 \\
& 1 \leq t_{c n} \leq 15 \\
& 5 \leq C_{m, h} \leq 100 \\
& 4 \leq C_{n, p} \leq 150 \\
& 0.4 \leq C_{a, h} \leq 4.5
\end{aligned}
$$

Additionally, as analyzed above, $d_{o p}$ depends on parameters such as $d_{N 0}, W R, \mathrm{t}_{\mathrm{cn}}, P_{c}, C_{m, h}, C_{n, p}$, and $C_{s}$. Hence, the optimum replaced nozzle diameter is described as follows:

$$
d_{o p}=f\left(d_{N 0}, W R, t_{c n}, P_{c}, C_{m, h}, C_{n, p}, C_{s}\right)
$$

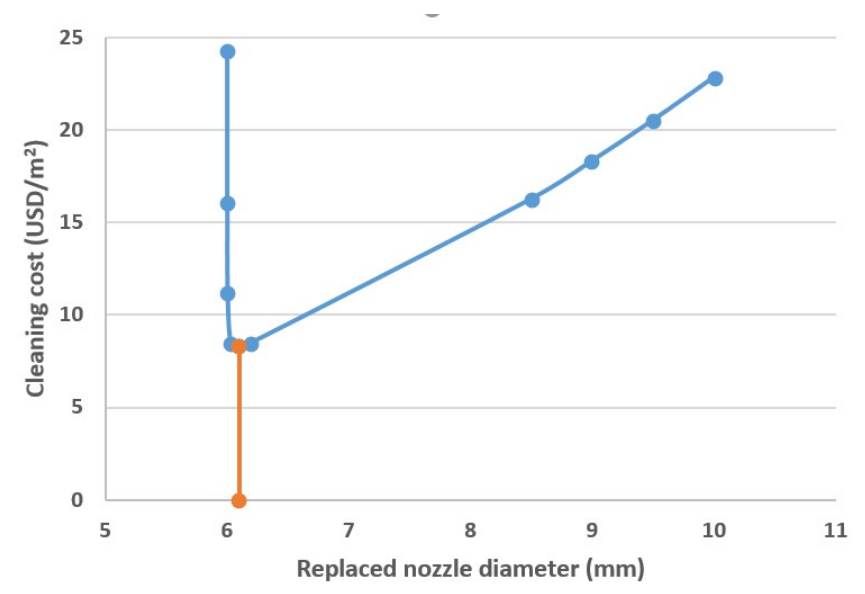

Figure 3: Cleaning cost versus nozzle diameter 


\section{EXPERIMENTAL DETAILS}

In this work, a series of meticulous experiments were performed to investigate the effect of the above mentioned factors on the optimum replaced nozzle diameter. The factors with levels are shown in Table 1. Each experiment is carried out with fixed parameters selected within the allowable adjustment range of the equipment.

Table 1: Factors and levels

\begin{tabular}{|l|c|l|l|l|}
\hline \multicolumn{1}{|c|}{ Factor } & Code & \multicolumn{1}{c|}{ Unit } & \multicolumn{1}{c|}{ Low } & \multicolumn{1}{c|}{ High } \\
\hline Initial nozzle diameter & $d_{N 0}$ & $\mathrm{~mm}$ & 5 & 12.5 \\
\hline Nozzle wear rate per hour & $W R$ & $10^{-3} \mathrm{~mm} / \mathrm{h}$ & 4 & 5.3 \\
\hline Time for changing a nozzle & $t_{c n}$ & $\mathrm{~min}$. & 1 & 15 \\
\hline Compressor power & $P_{c}$ & $\mathrm{~kW}$ & 4 & 80 \\
\hline Machine cost per hour & $C_{m, h}$ & $\mathrm{USD} / \mathrm{h}$ & 5 & 100 \\
\hline Nozzle cost per piece & $C_{n, p}$ & $\mathrm{USD} / \mathrm{piece}$ & 4 & 150 \\
\hline Cost of sand & $C_{s}$ & $\mathrm{USD} / \mathrm{kg}$ & 0.4 & 4.5 \\
\hline
\end{tabular}

To find out the effects of sandblasting process parameters on the output factor, an experimental method called "screening experiment" was applied. The screening experiment method is conducted for purposes such as finding out the main influencing factors on the output factors, estimating the influence of the factors, determining the degree of interaction effects between factors; establishing the first-order relationship between input factors and output factors. Minitab 18 software was selected for the design of the experiment and data analysis.

\section{RESULTS AND DISCUSSIONS}

The influences of the input factors on the optimum replaced nozzle diameter are illustrated in Figure 4. As shown in Figure 4 , the initial nozzle diameter is the factor with the most powerful influence on the optimum replaced nozzle diameter. Other factors including $W R, t_{c n}, P_{c}, C_{m, h}, C_{n, p}$, and $C_{s}$ have insignificant influence.

Additionally, Figure 5 shows the Normal Plot of the standardized effects. The input factors including $d_{N 0}, W R, t_{c n}$, $P_{c}, C_{m h}, C_{n p}$, and $C_{s}$ were represented by A, B, C, D, E, F, and G, respectively. The factor A (initial nozzle diameter) is the most influential factor for the optimum replaced nozzle diameter. It has a positive standardized effect. The influence of other factors and the interactions are negligible.

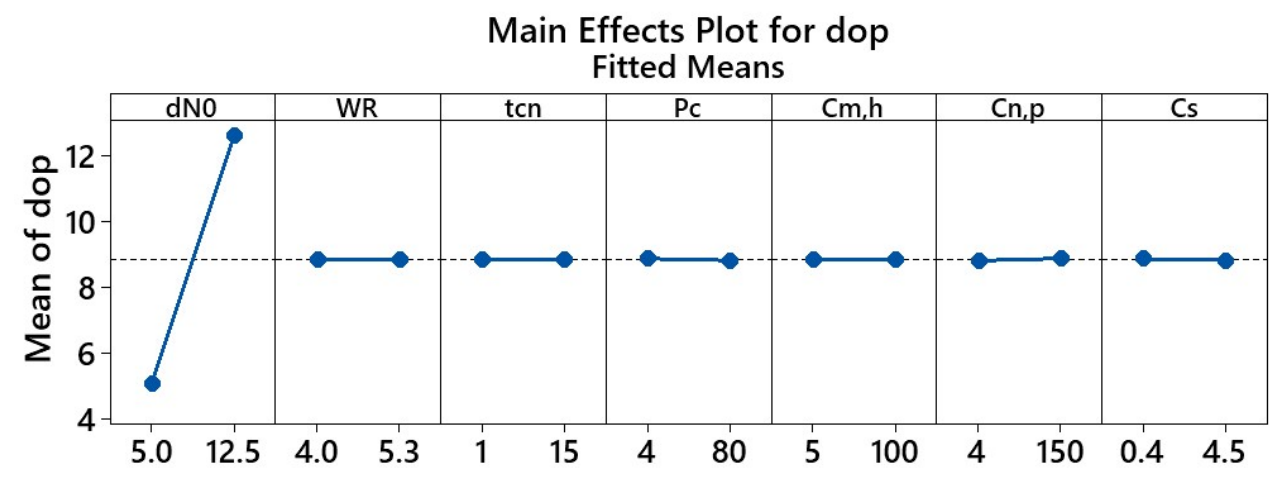

Figure 4: The main effects plot for the optimum replaced nozzle diameter 


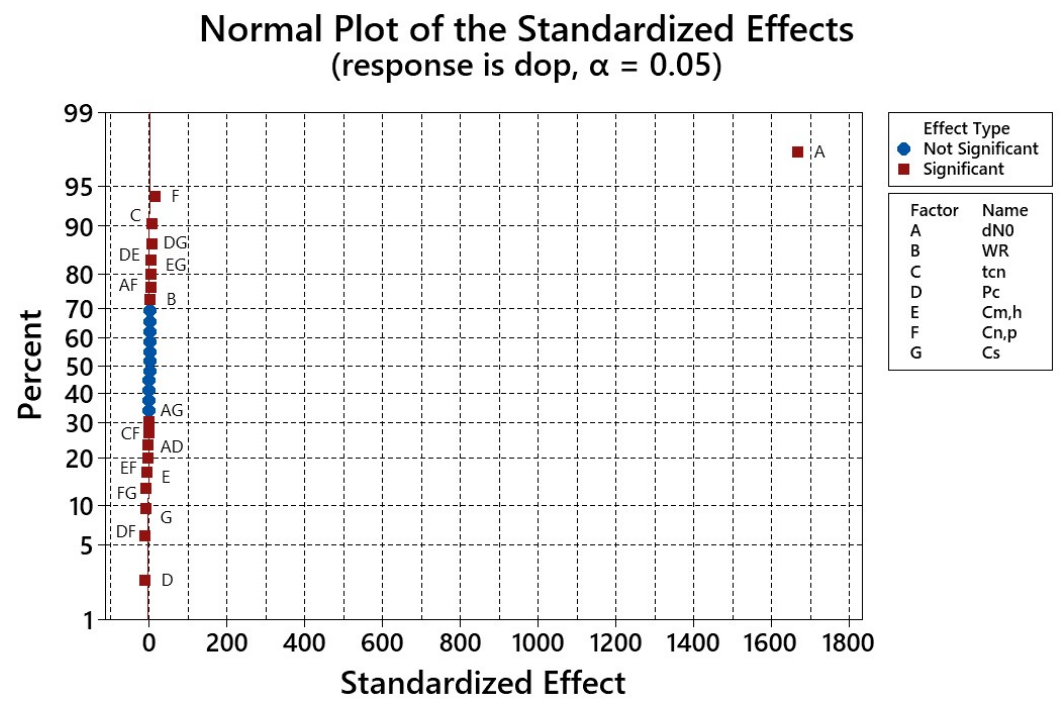

Figure 5: Normal Plot for $d_{o p}$

The results of $d_{o p}$ obtained from the experiments are shown in Table 2. Also, an empirical model was developed for calculating the optimum replaced nozzle diameter as the equation (17):

$\mathrm{d}_{\mathrm{op}}=-0.0206+1.00607 \mathrm{~d}_{\mathrm{N} 0}+0.00877 \mathrm{WR}+0.003278 \mathrm{t}_{\mathrm{cn}}-0.000409 \mathrm{P}_{\mathrm{c}}-0.000555 \mathrm{C}_{\mathrm{m}, \mathrm{h}}+0.001074 \mathrm{C}_{\mathrm{n}, \mathrm{p}}-0.00779$

$\mathrm{C}_{\mathrm{s}}-0.000046 \mathrm{~d}_{\mathrm{N} 0} * \mathrm{P}_{\mathrm{c}}+0.000030 \mathrm{~d}_{\mathrm{N} 0} * \mathrm{C}_{\mathrm{n}, \mathrm{p}}-0.000640 \mathrm{~d}_{\mathrm{N} 0} * \mathrm{C}_{\mathrm{s}}-0.000010 \mathrm{t}_{\mathrm{cn}} * \mathrm{C}_{\mathrm{n}, \mathrm{p}}+0.000006 \mathrm{P}_{\mathrm{c}} * \mathrm{C}_{\mathrm{m}, \mathrm{h}}-0.000008$

$\mathrm{P}_{\mathrm{c}} * \mathrm{C}_{\mathrm{n}, \mathrm{p}}+0.000161 \mathrm{P}_{\mathrm{c}} * \mathrm{C}_{\mathrm{s}}-0.000003 \mathrm{C}_{\mathrm{m}, \mathrm{h}} * \mathrm{C}_{\mathrm{n}, \mathrm{p}}+0.000102 \mathrm{C}_{\mathrm{m}, \mathrm{h}} * \mathrm{C}_{\mathrm{s}}-0.000123 \mathrm{C}_{\mathrm{n}, \mathrm{p}} * \mathrm{C}_{\mathrm{s}}$

Table 3 indicates the analysis of variance. According to the table of ANOVA, the initial nozzle diameter is the most influential input factor on the optimum replaced nozzle diameter. It contributes $99.965 \%$ to the total effect. The effects of other factors and the interactions are negligible (less than 1\%). Otherwise, the effects of all factors and interactions on the optimum replaced nozzle diameter are statistically significant with P-value less than 0.05 . With a determination coefficient R-sq of $100 \%$, it means that the model is a good model for calculating the optimum replaced nozzle diameter.

Table 2: Experimental results

\begin{tabular}{|c|c|c|c|c|c|c|c|c|}
\hline \multirow{2}{*}{ RunOrder } & \multicolumn{7}{|c|}{ Sandblasting process parameters } & $\begin{array}{c}\text { Optimum replaced nozzle } \\
\text { diameter }\end{array}$ \\
\cline { 2 - 9 } & $\boldsymbol{d}_{\boldsymbol{N} \mathbf{0}}$ & $\boldsymbol{W} \boldsymbol{R}$ & $\boldsymbol{t}_{\boldsymbol{c n}}$ & $\boldsymbol{P}_{\boldsymbol{c}}$ & $\boldsymbol{C}_{\boldsymbol{m} \boldsymbol{h}}$ & $\boldsymbol{C}_{\boldsymbol{n} \boldsymbol{p}}$ & $\boldsymbol{C}_{\boldsymbol{s}}$ & $\boldsymbol{d}_{\boldsymbol{o p}}$ \\
\hline 1 & 5 & 4 & 15 & 80 & 100 & 4 & 0.4 & 5.05 \\
\hline 2 & 12.5 & 4 & 15 & 4 & 100 & 150 & 4.5 & 12.62 \\
\hline 3 & 5 & 4 & 15 & 4 & 5 & 4 & 4.5 & 5.05 \\
\hline 4 & 5 & 5.3 & 1 & 4 & 5 & 150 & 0.4 & 5.25 \\
\hline 5 & 5 & 4 & 15 & 4 & 100 & 150 & 0.4 & 5.12 \\
\hline 6 & 12.5 & 4 & 15 & 4 & 5 & 150 & 0.4 & 12.85 \\
\hline$\ldots$ & & & & & & & & \\
\hline 127 & 5 & 5.3 & 15 & 80 & 100 & 4 & 4.5 & 5.06 \\
\hline 128 & 12.5 & 4 & 15 & 4 & 5 & 4 & 4.5 & 12.58 \\
\hline
\end{tabular}


Table 3: The ANOVA

\begin{tabular}{|c|c|c|c|c|c|c|}
\hline Source & DF & Adj SS & Adj MS & F-Value & P-Value & $\%$ \\
\hline Model & 17 & 1818.22 & 106.95 & 162995.69 & $0.000^{\mathrm{a}}$ & 99.996 \\
\hline Linear & 7 & 1818.03 & 259.72 & 395804.67 & $0.000^{\mathrm{a}}$ & 99.985 \\
\hline$d_{N 0}$ & 1 & 1817.67 & 1817.67 & 2770079.82 & $0.000^{\mathrm{a}}$ & 99.965 \\
\hline$W R$ & 1 & 0.00 & 0.00 & 6.34 & $0.013^{\mathrm{a}}$ & 0.000 \\
\hline$t_{c n}$ & 1 & 0.04 & 0.04 & 59.21 & $0.000^{\mathrm{a}}$ & 0.002 \\
\hline$P_{c}$ & 1 & 0.10 & 0.10 & 145.02 & $0.000^{\mathrm{a}}$ & 0.005 \\
\hline$C_{m, h}$ & 1 & 0.02 & 0.02 & 27.15 & $0.000^{\mathrm{a}}$ & 0.001 \\
\hline$C_{n, p}$ & 1 & 0.15 & 0.15 & 221.17 & $0.000^{\mathrm{a}}$ & 0.008 \\
\hline$C_{S}$ & 1 & 0.06 & 0.06 & 94.01 & $0.000^{\mathrm{a}}$ & 0.003 \\
\hline 2-Way Interactions & 10 & 0.19 & 0.02 & 29.40 & $0.000^{\mathrm{a}}$ & 0.010 \\
\hline$d_{N 0} * P_{c}$ & 1 & 0.01 & 0.01 & 8.20 & $0.005^{\mathrm{a}}$ & 0.001 \\
\hline$d_{N 0} * C_{n, p}$ & 1 & 0.01 & 0.01 & 13.13 & $0.000^{\mathrm{a}}$ & 0.001 \\
\hline$d_{N 0} * C_{S}$ & 1 & 0.00 & 0.00 & 4.73 & $0.032^{\mathrm{a}}$ & 0.000 \\
\hline$t_{c n} * C_{n, p}$ & 1 & 0.00 & 0.00 & 5.34 & $0.023^{\mathrm{a}}$ & 0.000 \\
\hline$P_{c} * C_{m, h}$ & 1 & 0.02 & 0.02 & 25.73 & $0.000^{\mathrm{a}}$ & 0.001 \\
\hline$P_{c} * C_{n, p}$ & 1 & 0.07 & 0.07 & 103.61 & $0.000^{\mathrm{a}}$ & 0.004 \\
\hline$P_{c} * C_{s}$ & 1 & 0.02 & 0.02 & 30.86 & $0.000^{\mathrm{a}}$ & 0.001 \\
\hline$C_{m, h} * C_{n, p}$ & 1 & 0.01 & 0.01 & 17.43 & $0.000^{\mathrm{a}}$ & 0.001 \\
\hline$C_{m, h} * C_{s}$ & 1 & 0.01 & 0.01 & 19.20 & $0.000^{\mathrm{a}}$ & 0.001 \\
\hline$C_{n, p} * C_{s}$ & 1 & 0.04 & 0.04 & 65.75 & $0.000^{\mathrm{a}}$ & 0.002 \\
\hline Error & 110 & 0.07 & 0.00 & - & - & 0.004 \\
\hline Total & 127 & 1818.30 & - & - & - & 100.000 \\
\hline
\end{tabular}

The normal probability plot of the optimum replaced nozzle diameter is indicated in Figure 6. It expressed that the points on this normal probability plot of $d_{o p}$ form a nearly linear pattern meaning that the normal distribution is a suitable model in this study. In other words, the model established is a good model for calculating the optimum replaced nozzle diameter.

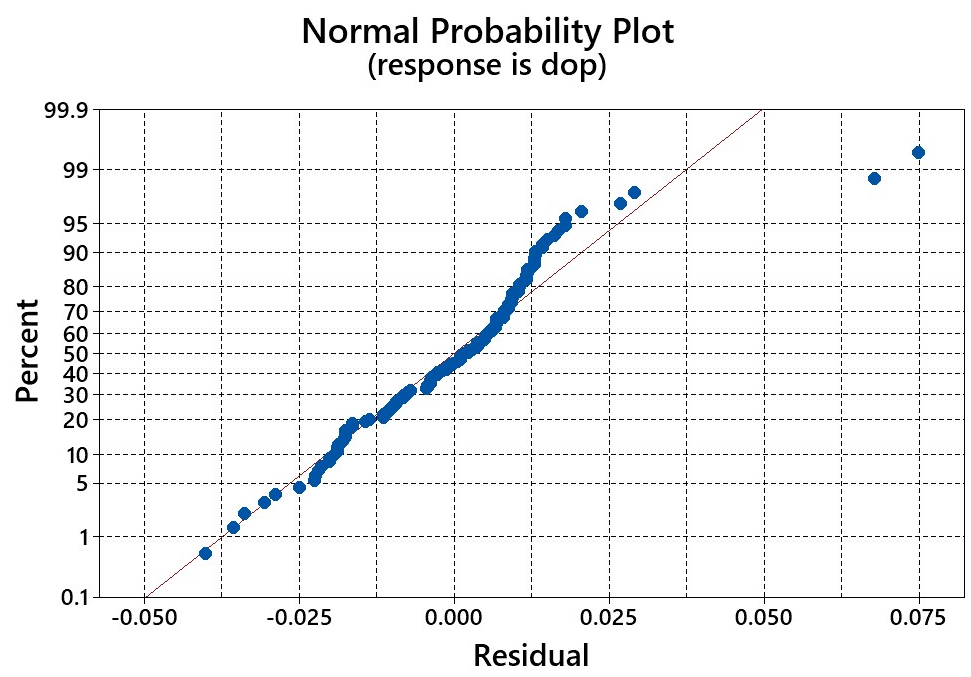

Figure 6: Normal Probability plot of $d_{o p}$ 


\section{CONCLUSIONS}

In the current study, a study on optimization of replaced tungsten carbide nozzle diameter for minimum cleaning costs during abrasive blasting with quartz sand was conducted. Additionally, the effects of process parameters on the optimum replaced nozzle diameter were investigated. These conclusions have been drawn:

- For certain process parameters, there exists an optimal replaced nozzle diameter at which the cleaning cost is minimum.

- The initial nozzle diameter is the most influential input factor on the optimum replaced nozzle diameter. It contributes $99.965 \%$ to the total effect. The influences of other factors and the interactions are negligible.

- The empirical model used for determining the optimum replaced nozzle diameter is considered to be statistically significant in this study.

\section{ACKNOWLEDGEMENTS}

The authors gratefully acknowledge Thai Nguyen University of Technology for supporting this work.

\section{REFERENCES}

1. Pi, V.N., and Duc, T.M.: 'A study on multi-objective optimization of abrasive blasting systems', in Editor (Ed.)^(Eds.): 'Book A study on multi-objective optimization of abrasive blasting systems' (Trans Tech Publ, 2010, edn.), pp. 29-34

2. Tilghman, B.C.: 'Sandblasting', US Patent No. 108, 408, 1870

3. https://www.marketresearchfuture.com/reports/abrasives-market-5391, accessed 24/4 2020

4. Woodward, M.J., and Judson, R.S.: 'The development of a high production abrasive water jet nozzle system', in Editor $(E d .)^{\wedge}(E d s$.$) : 'Book The development of a high production abrasive water jet nozzle system' (1987, edn.), pp. 217-226$

5. Hansink, J.D.: 'Economics of abrasive selection for shipyard use', Protective Coatings Europe, 1998, 3, pp. 25

6. omber, A.: 'Hydroblasting and Coating of steel structures' (Elsevier, 2003. 2003)

7. Pi, V.N., and Hoogstrate, A.: 'Cost optimization of abrasive blasting systems: A new and effective way for using blasting nozzles', in Editor (Ed.)^(Eds.): 'Book Cost optimization of abrasive blasting systems: A new and effective way for using blasting nozzles' (Trans Tech Publ, 2007, edn.), pp. 323-328

8. Vu Ngoc Pi, N.D.B., Nguyen Van Du, Phung The Chien: 'A new study on optimization of abrasive blasting system', Proceeding of the 11th conference on Science and Technology, October 21-23, 2009, pp. 143-148

9. Huo, J., Liu, S., Wang, Y., Muthuramalingam, T., and Pi, V.N.: 'Influence of process factors on surface measures on electrical discharge machined stainless steel using TOPSIS', Materials Research Express, 2019, 6, (8), pp. 086507

10. Phan, N.H., Van Duc, N., Van Bong, P., Muthuramalingam, T., Vu, N.P., and Hung, L.X.: 'Multi-responses Optimization of Process Parameters in Die-Sinking EDM Process on SKD11 Steel Using PSI Based Taguchi Method', in Editor (Ed.)^(Eds.): 'Book Multi-responses Optimization of Process Parameters in Die-Sinking EDM Process on SKD11 Steel Using PSI Based Taguchi Method' (Springer, 2019, edn.), pp. 493-499

11. Tran, T.H., Hoang, T.D., Le, H.K., Do, T.T., Bui, T.H., Nguyen, M.C., Luu, A.T., and Vu, N.P.: 'Analysis of Effects of Machining Parameters on Surface Roughness in Electrical Discharge Machining Tablet Shape Punches Using Taguchi Method', in Editor (Ed.)^(Eds.): 'Book Analysis of Effects of Machining Parameters on Surface Roughness in Electrical Discharge Machining Tablet Shape Punches Using Taguchi Method' (Trans Tech Publ, 2020, edn.), pp. 12-17 
12. Duc, T.A., Cuong, N.M., Tung, L.A., Hung, L.X., and Pi, V.N.: 'Effects of Process Parameters on Machining Time in Wire Electrical Discharge Machining of 9 CrSi Steel'

13. Thi Hong, T., Do Tam, T., Nguyen, M.C., Anh Tung, L., Ngoc Pi, V., Le Ky, H., Quoc Tuan, N., and Tien Dung, H.: 'Effects of Process Parameters on Surface Roughness in Wire-Cut EDM of 9CRSI Tool Steel', International Journal of Mechanical Engineering and Technology, 2019, 10, (3)

14. Hong, T.T., Do Thi Tam, N.M.C., Tung, L.A., Pi, V.N., Tuan, N.Q., and Dung, H.T.: 'EFFECTS OF PROCESS PARAMETERS ON SURFACE ROUGHNESS IN WIRE-CUT EDM OF 9CRSI TOOL STEEL'

15. Tu, H.X., Pi, V.N., and Jun, G.: 'A Study on Determination of Optimum Parameters for Lubrication in External Cylindrical Grinding Base on Taguchi Method', Key Engineering Materials, 2019, 796

16. Hung, L.X., Pi, V.N., Tung, L.A., Tu, H.X., Jun, G., and Long, B.: 'Determination of optimal exchanged grinding wheel diameter when internally grinding alloy tool steel 9CrSi', in Editor $(E d .)^{\wedge}(E d s$.$) : 'Book Determination of optimal exchanged$ grinding wheel diameter when internally grinding alloy tool steel 9CrSi' (IOP Publishing, 2018, edn.), pp. 012026

17. Tu, H.X., Jun, G., Hung, L., Tung, L., and Pi, V.: 'Calculation of optimum exchanged grinding wheel diameter when external grinding tool steel 9CrSi', Int. J. Mech. Eng. Robot. Res, 2019, 8, (1), pp. 59-64

18. Hung, L.X., Lien, V.T., Pi, V.N., and Long, B.T.: 'A study on coolant parameters in internal grinding of 9CrSi steel', in Editor $(E d .)^{\wedge}(E d s$.$) : 'Book A study on coolant parameters in internal grinding of 9CrSi steel' (Trans Tech Publ, 2019, edn.), pp. 24-$ 31

19. Kuppusamy, S., and Ramalingam, D.: 'Optimization of process parameters in CNC turning of Titanium alloy with carbide coated tool inserts using grey based Taguchi analysis', Journal of Advanced Mechanical Design, Systems, and Manufacturing, 2018, 12, (4), pp. JAMDSM0094-JAMDSM0094

20. Chen, Y., Chen, Y., Luo, W., and Zhang, G.: 'Theoretical and experimental investigation of accurately turning the TI worm tooth surface', Journal of Advanced Mechanical Design, Systems, and Manufacturing, 2015, 9, (2), pp. JAMDSM0022JAMDSM0022

21. 'http://www.nortonsandblasting.com/nsbnozzles2.html', Accessed April 15, 2020

22. 'https://clemcoindustries.com/products/accessories/boron-carbide-lined-metal-jacketed-bsd-series/', Accessed April 15, 2020 

